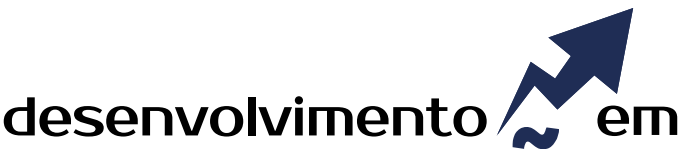 QUESTÃO
}

\section{Expansão Urbana e Vulnerabilidade Socioeconômica: Carto(Grafias) da Cidade}

http://dx.doi.org/10.21527/2237-6453.2019.46.268-286

Recebido: 8/11/2017

Aceito: $23 / 5 / 2018$

Luziana Maria Nunes de Queiroz ${ }^{1}$, lone Rodrigues Morais², Magdi Ahmed Aloufa³

\begin{abstract}
RESUMO
Este artigo problematiza a relação entre expansão urbana e vulnerabilidade socioeconômica, tendo como referência a Cidade de Caicó (Brasil) e como recorte temporal a década de 80 aos dias atuais. Nessa investida, analisou-se a expansão urbana de Caicó, por fases de ocorrência, considerando as variáveis população, economia e espacialização citadina e calculou-se os índices e níveis de vulnerabilidade socioeconômica da cidade, por zonas geográficas e bairros, a partir dos quais foi produzida cartografia relativa a essa temática. Metodologicamente, recorreu-se à pesquisa bibliográfica e documental. Assim, a cartografia da vulnerabilidade socioeconômica de Caicó, por zonas geográficas e bairros, revela que os índices e níveis relativos a este fenômeno não apresentam grandes variações, situando-se entre médio e muito baixo; todavia é a Zona Oeste que apresenta maior vulnerabilidade econômica, com o Bairro João Paulo II revelando o mais elevado índice na cidade. Outrossim, também se constata que, embora o Índice de Vulnerabilidade Socioeconômica por Bairros (IVSB) médio tenha sido registrado em bairros de formação antiga, sua ocorrência mostra-se mais contundente entre os bairros de formação recente. Nesse sentido, é possível inferir que, no caso da cidade de Caicó, a vulnerabilidade socioeconômica está associada ao processo de expansão urbana, visto que este fenômeno torna-se mais presente em bairros de formação recente, em geral situados na periferia das cidades, onde se concentram populações de menor poder aquisitivo e as políticas públicas são mais negligenciadas.
\end{abstract}

Palavras-chave: Cidade. Expansão urbana. Vulnerabilidade socioeconômica.

URBAN EXPANSION AND SOCIOECONOMIC VULNERABILITY: CARTO(GRAPHIES) OF A CITY

\begin{abstract}
This article problematizes relation between urban expansion and socioeconomic vulnerability, with reference in Caicó city (Brazil) and from 1980s to current days as temporal cut. Urban expansion of Caicó was analyzed by occurrence phases, taking into consideration population, economy and city specialty variables, calculating socioeconomic vulnerability indexes and levels by geographic zones and neighborhoods of that city, from which a cartography related to this thematic was produced. Methodologically, a document e bibliographic research was conducted. Thus, cartography of socioeconomic vulnerability in Caicó, by geographic zones and neighborhoods, reveals that indexes and levels related to this phenomenon do not present great variations, situating between medium and very low; however, West Zone presents highest socioeconomic vulnerability, being João Paulo II neighborhood one that holds city's highest index. Furthermore, It was found that although average Índice de Vulnerabilidade Socioeconômica por Bairros (IVSB) has been registered on ancient formation neighborhoods, its occurrence is stronger in recent formation neighborhoods. In this sense, It is possible to infer that socioeconomic vulnerability in Caicó city is associated to urban expansion process, once this phenomenon becomes more present in recent formation neighborhoods, generally situated in peripheries of cities, where lower purchasing power populations are located, and public politics are more neglected.
\end{abstract}

Keywords: City. Urban expansion. Socioeconomic vulnerability.

\footnotetext{
${ }^{1}$ Doutoranda do Programa de Pós-Graduação em Desenvolvimento e Meio Ambiente da Universidade Federal do Rio Grande do Norte. Professora da Universidade Federal do Rio Grande do Norte. luziana65@hotmail.com

${ }^{2}$ Doutora em Ciências Sociais pela Universidade Federal do Rio Grande do Norte. Professora dos Programas de Pós-graduação em Geografia e de Desenvolvimento e Meio Ambiente da Universidade Federal do Rio Grande do Norte. ionerdm@yahoo.com.br

${ }^{3}$ Doutora em Biologia e Fisiologia Vegetal pela Université Pierre et Marie Curie. Professora da Universidade Federal do Rio Grande do Norte. magdialoufal@gmail.com
} 
A partir da segunda metade do século 20 o Brasil passou a vivenciar um acelerado processo de expansão urbana, impulsionado principalmente pela industrialização e pela urbanização. Nesse contexto, não apenas aumentou o número de cidades, como também estas passaram a concentrar um maior contingente populacional.

A expansão urbana está diretamente associada às dinâmicas socioeconômica e política que ocorrem na cidade. Nessa perspectiva, afigura-se como um processo que assume importância nos estudos e nas iniciativas de pesquisadores, planejadores e gestores, tendo em vista que no âmbito do capitalismo, a cidade, como uma construção social e histórica (CARLOS, 2007), revela-se perpassada por desigualdades socioespaciais. Sendo assim, por vezes, o viver na cidade torna a população, sobretudo a mais pobre, vulnerável tanto do ponto de vista socioeconômico quanto ambiental.

Considerando o exposto, realizou-se uma investigação que problematiza a relação entre expansão urbana e vulnerabilidade socioeconômica. ${ }^{4}$ Parte-se da premissa de que, no decurso do processo de expansão urbana, os bairros de ocupação recente, por se localizarem grosso modo na periferia da cidade, apresentam índices e níveis de vulnerabilidade socioeconômica mais elevados, enquanto nos bairros de ocupação antiga esses indicadores são mais baixos, devido à influência das políticas públicas de infraestrutura urbana que negligenciam as áreas periféricas.

A pesquisa definiu como base empírica a cidade de Caicó, localizada no Estado do Rio Grande do Norte (Brasil), e como recorte temporal os anos 80 aos dias atuais. A opção por essa base empírica fundamenta-se no papel que Caicó assume no sistema urbano do Rio Grande do Norte, ${ }^{5}$ reconhecida como centro regional do Seridó. A centralidade urbano-regional de Caicó foi ratificada no estudo Regiões de Influência das Cidades - REGIC ${ }^{6}$ (IBGE..., 2010), no qual a cidade é classificada como um Centro sub-regional, de nível $A$, com raio de influência que inclusive extrapola a Região do Seridó potiguar, abrangendo 11 cidades do Rio Grande do Norte (Cruzeta, Ipueira, Jardim de Piranhas, Jardim do Seridó, Ouro Branco, São Fernando, São João do Sabugi, São José do Seridó, Serra Negra do Norte, Timbaúba dos Batistas e Parelhas) e uma cidade do Estado da Paraíba (São Bento). O recorte temporal justifica-se por ser esse o período em que a cidade passou a vivenciar o cenário pós-crise da cotonicultura, um dos pilares básicos da dinâmica econômica local e regional (Seridó).

Na perspectiva de investigar em que medida existe relação entre o processo de expansão urbana e o fenômeno da vulnerabilidade socioeconômica, delineou-se um itinerário de pesquisa norteado pelos seguintes questionamentos: Quais os aspectos que

\footnotetext{
${ }^{4}$ A pesquisa não contemplou a vulnerabilidade socioambiental, conforme Maior (2014), devido à falta de dados sobre os temas da dimensão ambiental relativos à cidade de Caicó.

${ }^{5}$ O município de Caicó localiza-se na Microrregião Geográfica do Seridó Ocidental, na Mesorregião Central Potiguar. Em 2010, contava com uma população de 62.709 habitantes, sendo 5.240 moradores rurais e 57.461 residentes urbanos; a taxa de urbanização do município correspondeu a 91,63\% (IBGE, 2016a). Quanto ao Índice de Desenvolvimento Humano Municipal - IDHM - Caicó destaca-se entre os municípios do interior do Nordeste, por ter apresentado um índice de 0,710 em 2010.

${ }^{6}$ De acordo com o Regic (IBGE, 2007), o centro sub-regional é definido como aquele que apresenta atividades de gestão menos complexas, tem área de atuação mais reduzida que o centro regional e seus relacionamentos com centros externos à sua própria rede ocorrem, em geral, apenas com as três metrópoles nacionais (São Paulo, Rio de Janeiro e Belo Horizonte). Levando em conta as medianas do quantitativo populacional, a classificação de centro sub-regional pode ser dividida em duas categorias: centro sub-regional A, posição atribuída a Caicó, e centro sub-regional B.
} 
marcaram o processo de expansão urbana de Caicó, segundo suas fases de ocorrência? Considerando a cartografia atual da cidade, como se configura a organização de bairros, em termos de ocupação antiga e de expansão urbana recente? Quais os níveis de vulnerabilidade socioeconômica da cidade de Caicó, por zonas geográficas e bairros? Como se apresentam esses níveis em termos de bairros de ocupação antiga e outros de formação recente?

Considerando esses questionamentos, definiu-se como objetivo geral: compreender a relação entre expansão urbana e vulnerabilidade socioeconômica na cidade de Caicó, considerando os anos 80 como divisor no seu processo de configuração espacial, e como objetivos específicos: analisar os aspectos que marcaram o processo de expansão urbana de Caicó e delimitaram suas fases de ocorrência; examinar aspectos do processo de configuração do espaço citadino em termos espaçotemporais, considerando os anos 80 como marco divisório; calcular os índices e níveis de vulnerabilidade socioeconômica de Caicó e produzir a cartografia da vulnerabilidade socioeconômica de Caicó.

Os procedimentos metodológicos utilizados nesta pesquisa corresponderam à pesquisa bibliográfica e documental. No que se refere à temática sobre o urbano, a pesquisa bibliográfica pautou-se em livros e artigos que tratam do tema, destacando-se Brandão (1992), Carlos (2007) e Clementino e Souza (2009) e, na perspectiva de contemplar a base empírica, também se efetivou por meio de obras da historiografia regional/local, de autores como: Araújo (2008), Clementino (1987), Dantas (2001), Morais (1999) e Faria (2011). Ainda no âmbito desse tema, a pesquisa documental correspondeu ao uso de representações cartográficas da cidade (espacialização da cidade por bairros), que retratavam diferentes períodos, obtidas nas seguintes fontes: Morais (1999), Agência dos Correios (2014); Companhia de Águas e Esgotos do Rio Grande do Norte - Caern (2015); Instituto Brasileiro de Geografia e Estatística - IBGE (2016a).

Quanto à temática vulnerabilidade socioeconômica, evidenciada em alguns estudos como uma dimensão da vulnerabilidade socioambiental, buscou-se as leituras de Abramovay et al (2002), Almeida (2010), Alves et al (2010a, 2010b), Alves (2006), Deschamps (2004), Hogan e Marandola Júnior (2006), Maior (2014) e Priem e Shaffer (2001).

Entre esses trabalhos ressalta-se Vulnerabilidade Socioambiental e Expansão Urbana: uma proposta metodológica para análise da cidade de João Pessoa, de Mônica Maria Souto Maior (2014), no qual é apresentada uma metodologia para definição do Índice Geral de Vulnerabilidade Socioambiental por Bairro - IGVSB ${ }^{7}$ - para a referida cidade. De acordo com a proposição de Maior (2014), a vulnerabilidade socioambiental apresenta duas dimensões: socioeconômica e ambiental. A vulnerabilidade socioeco-

\footnotetext{
Maior (2014, p. 86) procedeu à identificação e à análise comparativa dos modelos brasileiros de mensuração da vulnerabilidade socioambiental e, a partir deles, desenvolveu uma proposta metodológica objetivando a geração do que chamou de "Índice Geral de Vulnerabilidade Socioambiental por Bairro - IGVSB -", para a cidade de João Pessoa/PB. Esse estudo pautou-se na análise de cinco modelos - Hogan e Marandola Júnior (2006), Deschamps (2004; 2006), Almeida (2010) e Alves et al (2010a; 2010b) - a partir dos quais foram definidos 29 indicadores socioeconômicos e cinco indicadores socioambientais. Segundo a metodologia de Maior (2014), o conjunto dos indicadores foi estatística e analiticamente tratado por dimensão (socioeconômica e ambiental), tema, grupo de indicadores, indicadores e relação com a vulnerabilidade (se negativa ou positiva). A relação de cada indicador com o processo de vulnerabilidade se estabelece a partir da perspectiva de que essa relação é "positiva - quando, à medida que a variável cresce, ela contribui para a diminuição da vulnerabilidade - e negativa - quando, à medida que a variável cresce, ela contribui para o aumento da vulnerabilidade" (MAIOR, 2014).
} 
nômica abrange os temas condições domiciliares, infraestrutura urbana, condições dos chefes de família, composição familiar e dependência, situação educacional da família, renda, situação do trabalho. A vulnerabilidade ambiental abrange o tema comunidades em risco.

Considerando a base empírica deste estudo - cidade de Caicó - a aplicação dessa metodologia apresentou como obstáculo a ausência de dados acerca da vulnerabilidade ambiental. Em decorrência, a análise foi realizada tendo por referência a vulnerabilidade socioeconômica (IVSB), conforme Maior (2014). Para a geração do IVSB, segundo Maior (2014), fez-se necessária a compilação de dados do Censo Demográfico 2010 (IBGE, 2016a). Neste sentido, impôs-se um outro obstáculo, visto que os dados estatísticos relativos ao município de Caicó foram publicados pelo IBGE por setor censitário. Desta forma, procedeu-se ao cotejamento de informações e a sobreposição entre as representações cartográficas da cidade de Caicó, anteriormente referidas, e o mapa da cidade por setores censitários produzido pelo IBGE. O resultado desse processo pode ser visualizado na Figura 1.

Figura 1 - Cidade de Caicó por Bairros e Setores Censitários - 2016

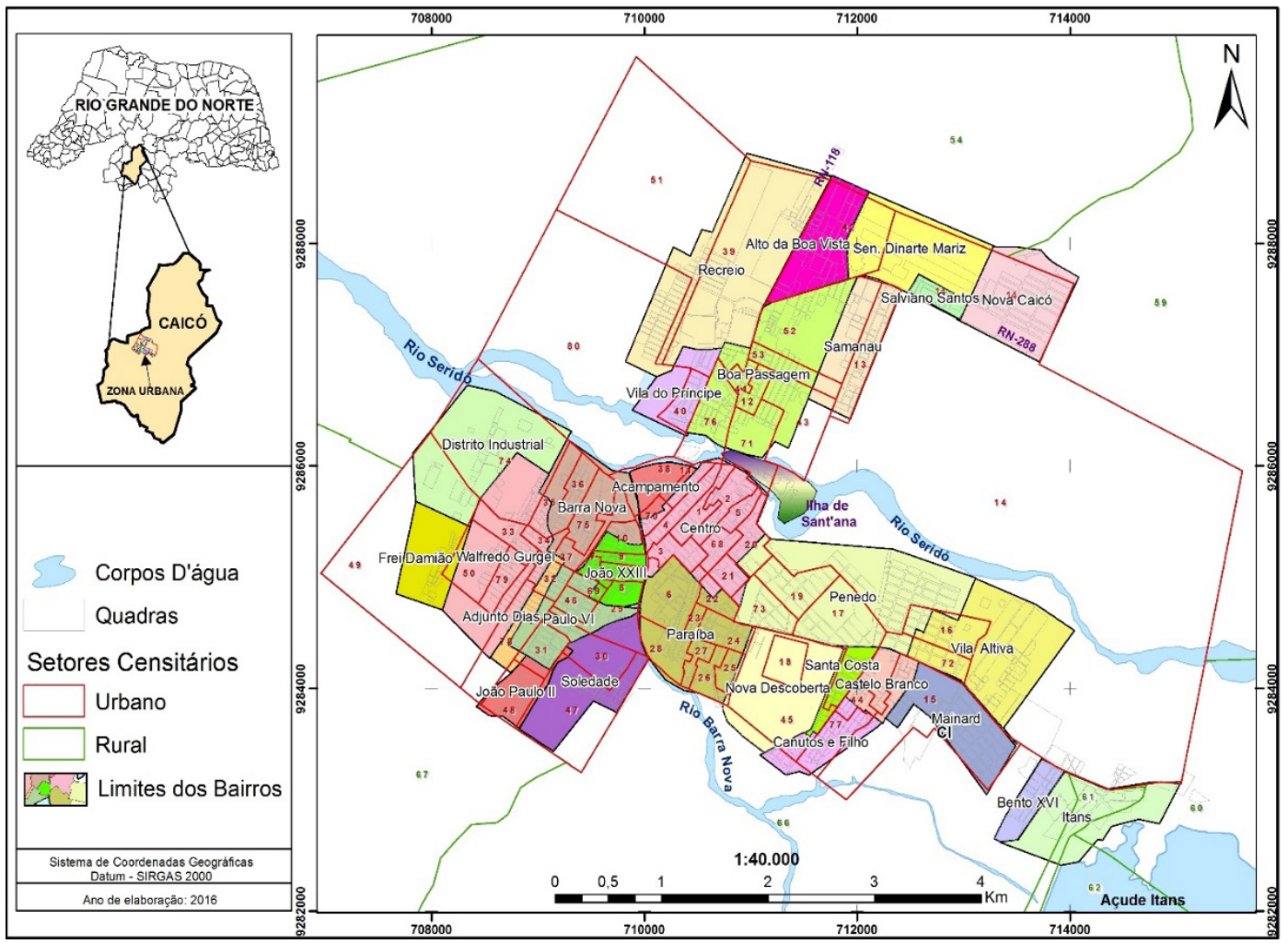

Fonte: AGÊNCIA DOS CORREIOS (2014); COMPANHIA... (2015); IBGE (2016a).

A sobreposição entre as representações cartográficas da cidade de Caicó ${ }^{8}$ permitiu identificar a correspondência entre os bairros e os respectivos setores censitários. ${ }^{9}$

\footnotetext{
${ }^{8}$ O espaço citadino de Caicó não se encontra oficialmente delimitado em bairros (exceto o Bairro Paraíba, localizado na Zona Sul), embora existam os decretos de criação nos quais constam a sua identificação. Não obstante, para fins de realização deste estudo, considerou-se a existência de 29 bairros, distribuídos pelas zonas centro, leste, oeste, norte e sul.

${ }^{9}$ De acordo com o IBGE (2010), Caicó possui 80 setores censitários, dos quais 12 estão totalmente inseridos na zona rural. São eles: 54, 55, 56, 57, 58, 59, 62, 63, 64, 65, 67 e 76. Por essa razão não foram considerados neste estudo.
} 
Considerando a definição prévia da relação entre indicadores e vulnerabilidade - positiva quando favorece o seu crescimento e negativa quando contribui para sua diminuição - recorreu-se às seguintes fórmulas para calcular o IVSB da cidade de Caicó, tendo por base inicialmente os setores censitários:

Indicador com relação negativa: I = (M-x)/(M-m).

Indicador com relação positiva: I = $(x-m) /(M-m)$.

Onde:

I = índice calculado para cada setor censitário da cidade;

$\mathrm{x}=$ valor para cada variável em cada setor censitário;

$\mathrm{m}=$ valor mínimo identificado para todos os setores censitários;

$M=$ valor máximo identificado para todos os setores censitários.

Após a aplicação dessas fórmulas, considerando os indicadores por setor censitário de Caicó, procedeu-se aos seguintes cálculos, considerando as situações descritas a seguir:

- Nos casos em que a delimitação do setor censitário coincidiu com a do bairro, o indicador logo foi assumido como sendo do bairro.

- Nos casos em que um único bairro apareceu subdividido em dois ou mais setores censitários, foi realizada a média aritmética dos indicadores obtidos pelos referidos setores, de modo a se estabelecer um indicador para o bairro.

- Nos casos em que um setor censitário abrangeu mais de um bairro, o indicador gerado para este setor deve ser considerado para o bairro onde este se apresenta com maior extensão; essa configuração territorial - bairro/setor censitário - foi assumida na cartografia do citado bairro.

Feitos esses procedimentos, chegou-se à geração do IVSB da cidade de Caicó. Como os indicadores apresentam diferentes unidades de medida, estes foram transformados em índices, que assumem uma escala de zero (0) a um (1). A partir dos dados obtidos realizou-se a classificação dos índices em níveis de vulnerabilidade socioeconômica (Quadro 1), conforme metodologia indicada por Maior (2014).

Quadro 1 - Classificação dos índices e níveis de vulnerabilidade socioeconômica

\begin{tabular}{|c|c|c|}
\hline Índice (0-1) & Nível de vulnerabilidade socioeconômica & Coloração \\
\hline $1,0000-0,8001$ & Muito alto & \\
\hline $0,8000-0,6001$ & Alto & \\
\hline $0,6000-0,4001$ & Médio & \\
\hline $0,4000-0,2001$ & Baixo & \\
\hline $0,2000-0,0000$ & Muito baixo & \\
\hline
\end{tabular}

Fonte: MAIOR (2014).

Delineado o percurso da investigação, justifica-se a delimitação temática pela importância que os estudos urbanos assumem em um contexto no qual a cidade passou a ser o principal lócus de concentração das pessoas. Ademais, no Brasil, parcela significativa da população que reside na cidade, especialmente a mais pobre, vive (ou sobrevive) em condições de vulnerabilidade socioeconômica, o que está, em parte, associado 
à forma como os espaços que ocupam são (des)tratados pelos poderes públicos. Outrossim, a partir da pesquisa bibliográfica, tornou-se reconhecível que os estudos acerca da vulnerabilidade, seja socioeconômica, ambiental ou socioambiental, priorizaram grandes cidades e/ou capitais de Estado. Essa constatação despertou o interesse em pesquisar sobre o fenômeno da vulnerabilidade socioeconômica associado à expansão urbana, considerando outra escala de cidade.

Ressalta-se que estudos com essa abordagem contribuem com as análises teórico-metodológicas sobre a temática e podem servir de subsídios ao planejamento, a gestão urbana e a ação da população no sentido de reivindicar iniciativas que visem a reduzir ou superar a condição de vulnerabilidade existente.

\section{DINÂMICA CITADINA: Fases da Expansão Urbana}

No âmbito das reflexões acerca da cidade têm-se diferentes perspectivas de abordagens, entre as quais se destaca aquela que a considera como uma construção humana, portanto uma produção histórica e social,

[...] e nesta dimensão aparece como trabalho materializado, acumulado ao longo do processo histórico de uma série de gerações. Expressão e significação da vida humana, obra e produto, processo histórico cumulativo, a cidade contém e revela ações passadas, ao mesmo tempo em que o futuro, que se constrói nas tramas do presente - o que nos coloca diante da impossibilidade de pensar a cidade separada da sociedade e do momento histórico analisado (CARLOS, 2007, p. 11).

Apresentando-se como um espaço marcado pela mutabilidade, a cidade torna-se condicionante e reflexo dos processos sociais que nela ocorrem ou sobre ela repercutem, refletindo-os em sua espacialização, ou seja, em sua organização espacial. No âmbito desses processos ressalta-se a expansão urbana.

Segundo Clementino e Souza (2009), o processo de expansão urbana pode ser ocasionado por dois fenômenos distintos: transbordamento urbano e adensamento populacional. O primeiro refere-se à periferização de um centro principal sobre municípios vizinhos, devido, entre outros motivos, às especificidades da legislação, por novas relações do mercado imobiliário e menor crescimento populacional da cidade-polo. O segundo resulta, em grande parte, dos processos de migração e crescimento demográfico, acarretando o aumento da mancha urbana (área).

A análise empreendida em relação à cidade de Caicó abordou a expansão urbana na perspectiva do adensamento populacional, com base nas variáveis população, economia e espacialização citadina (leia-se configuração dos bairros). Nesse sentido, não obstante o recorte temporal da pesquisa (a partir dos anos 80 ) considerou-se a ocorrência de três fases de expansão urbana em Caicó. 
A primeira fase da expansão urbana compreende desde a origem ${ }^{10}$ de Caicó, no século 18 , até a década de 1930 . No contexto em que surgiu a povoação que deu origem à cidade, o espaço era ocupado pela pecuária, primeira atividade a se desenvolver na região do Seridó. Entre o final do século 19 e as primeiras décadas do século 20, o processo de expansão urbana de Caicó foi marcadamente lento, embora já possuísse alguns serviços de interesse da coletividade, tais como Agência Postal, Escola Primária, Comarca, Mercado Público Municipal, Prefeitura e Cartório Judiciário (MORAIS, 1999). Nesse período a cidade era apenas um pequeno núcleo urbano que tinha na Igreja de Sant'Anna o seu ponto central e no binômio gado-algodão a base da economia do município.

A segunda fase de expansão urbana compreende a década de 40 à década de 70 , período marcado pelo auge e também pela crise da cotonicultura. Do ponto de vista econômico, a cotonicultura, entre o final do século 19 e os primeiros anos da década de 70, instituiu-se como uma produção comercial voltada para a exportação, cumprindo uma trajetória ascendente, que a elevou à condição de uma das mais importantes economias do Rio Grande do Norte. Nesse contexto, o Seridó tornou-se referência da produção algodoeira (especialmente do algodão mocó) nos mercados nacional e internacional, entre a década de 40 e os primeiros anos da década de 70.

Na condição de centro regional, Caicó foi diretamente afetada pela dinâmica econômica produzida pelo binômio algodão-pecuária, refletindo-se no crescimento da população, especialmente a urbana (Tabela 1).

Tabela 1 - População total, urbana e rural de Caicó - 1940 - 1970

\begin{tabular}{c|c|c|c|}
\hline \multirow{2}{*}{ Censo } & \multicolumn{3}{|c|}{ População } \\
\cline { 2 - 4 } & Total & Urbana & Rural \\
\hline 1940 & 25.233 & 4.636 & 20.597 \\
1950 & 24.214 & 7.755 & 16.459 \\
1960 & 27.447 & 16.233 & 11.214 \\
1970 & 36.521 & 24.538 & 11.983 \\
\hline
\end{tabular}

Fonte: Censos Demográficos do IBGE (2016a).

Os dados do Censo de 1940 revelam a predominância da população rural sobre a urbana no município de Caicó, o que se justificava pelo fato de que a principal atividade econômica da época era a produção de algodão e a pecuária. Não obstante a hegemonia da população rural, os resultados do Censo de 1950 já apontavam para a tendência de crescimento da população urbana, que registrou a expressiva taxa de $67,27 \%$. Essa propensão manteve-se entre 1950 e 1960, quando a taxa de crescimento da população urbana atingiu 109\%, o maior já registrado na história do município, e houve uma redução de $46,77 \%$ de moradores rurais. Nesse censo a população urbana passou a ser predominante.

Esse padrão de comportamento populacional está associado ao ciclo promissor do algodão, que se instituiu entre as décadas de 40 e 60, que trouxe muitos benefícios para Caicó, possibilitando o surgimento e a melhoria de vários serviços e equipamen-

\footnotetext{
${ }^{10} \mathrm{~A}$ cidade tem sua origem vinculada à povoação, que foi instalada oficialmente em 7 de julho de 1735 , e cuja elevação à condição de município-vila, sob o nome de Vila Nova do Príncipe, ocorreu em 31 de julho de 1788. Somente em 1868 passou a ser Cidade do Príncipe, denominação que mudou para Seridó em 1890; nesse mesmo ano voltou a chamar-se Caicó (DANTAS, 2001, p. 100).
} 
tos urbanos, como instituições de ensino, emissora de rádio, cemitério, cinema, hotéis, abrigo, lojas comerciais (ARAÚJO, 2008). Nesse período, a cidade ampliou os serviços de saúde, educação, comunicação, como expressa Morais (1999, p. 92):

Na área da saúde com a Maternidade de Caicó (1947), o posto de Puericultura e o hospital do Seridó, na área da educação contavam com 10 escolas primárias, além da Escola Normal Regional de Caicó (1954) e os ginásios: Diocesano Seridoense e Santa Terezinha, e tinha duas bibliotecas - Olegário Vale e Prof. Pedro Gurgel, na área de serviços destacava-se a atuação do Rotary Club e da Loja Maçônica TrabaIho e Fraternidade, fundados em 1959.

Na década de 50 a cidade passou a contar com três indústrias de beneficiamento do algodão: Diniz \& Dantas S.A., Exportadora Dinarte Mariz S.A. e Algodoeira Seridó Comércio e Indústria S.A. (MORAIS, 1999), e ampliou ainda mais a infraestrutura, mediante a instalação de clubes, instituições públicas, bancos, casas comerciais, indústrias, telefonia, cinema, frigoríficos, açougues, bem como a pavimentação de ruas, fornecimento de energia e água, entre outros. Entre essas benfeitorias destacam-se a construção do Hospital do Seridó e a instalação do Batalhão Rodoviário de Engenharia. Para Araújo (2008, p. 23-24),

esses tempos de auge, marcados pelo desenvolvimento acelerado da atividade algodoeira, foram sentidos de maneira mais intensa na cidade, durante as décadas de 1950 e de 1960, quando se deu a instalação, sobretudo através de iniciativas públicas, de novos serviços, elementos e equipamentos urbanos na malha citadina caicoense.

Sob a ótica do sítio urbano, em 1950 Caicó era uma pequenina cidade, cujo território sequer ocupava totalmente o terreno delimitado pelos rios Seridó e Barra Nova (Figura 2).

Figura 2 - Cidade de Caicó - 1950

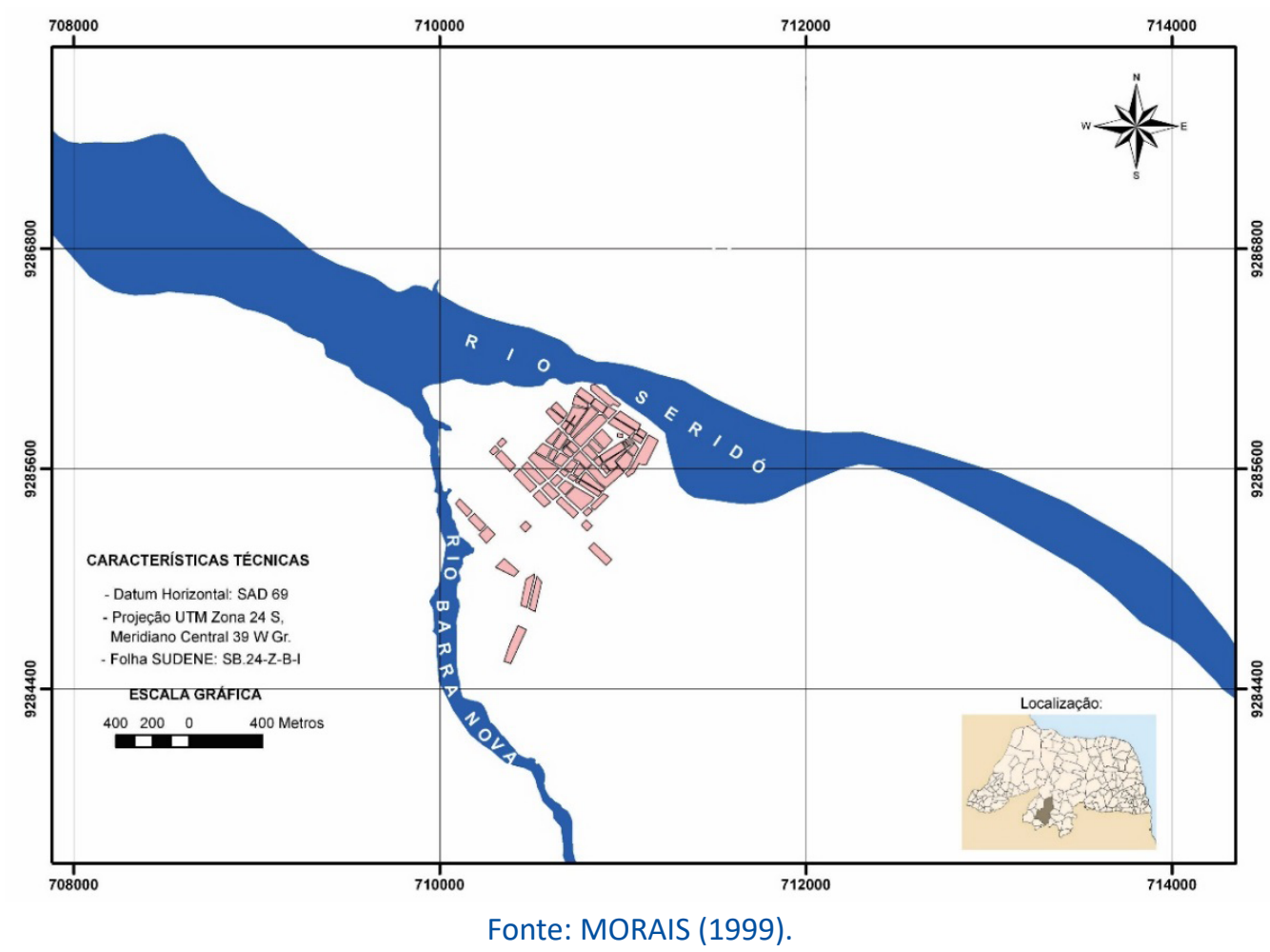


No que se refere ao sítio urbano, o aumento da população e os investimentos estruturais ocorridos na década de 60 aceleraram a expansão de Caicó, de modo que seus limites ultrapassaram os dois rios que a cercavam, o Seridó e o Barra Nova. Segundo Morais (1999), esse processo de crescimento ocasionou alterações na cartografia citadina, com a inserção dos bairros Barra Nova, Boa Passagem, Penedo, Nova Descoberta, Acampamento, João XXIII e a expansão do Bairro Paraíba. Esse crescimento urbano, entretanto, sem o devido planejamento, contribuiu para um processo de ocupação desordenada do solo. Ressalta-se, ainda, que as carências estruturais e de possibilidade de trabalho legalizado eram vulnerabilidades dessa época dourada.

Já em meados da década de 70, todavia, a cotonicultura começou a declinar em decorrência da conjugação de fatores econômicos, políticos e naturais. ${ }^{11}$ Nesse período começou a desestabilização da produção algodoeira no Seridó, o que provocou consideráveis impactos negativos na economia da região.

O setor passava de estados de súbita e desenfreada euforia para o desalento e pânico, evidenciando a vulnerabilidade de uma estrutura que depende de fatores externos para colocar adequadamente sua produção no mercado (CLEMENTINO, 1987, p. 208).

Consolidado o quadro de crise econômica no final da década de 70, suas repercussões tiveram impactos na zona rural, entre os quais ressalta-se a migração rural-urbana pela falta de trabalho no campo, e nas cidades, que passaram a receber os migrantes, o que gerou forte pressão sobre o mercado de trabalho, os serviços públicos, entre outros (MORAIS, 1999). Além da migração rural-urbana, na condição de centro regional Caicó tornou-se ponto de convergência também do deslocamento urbano-urbano, haja vista os fluxos de pessoas das pequenas cidades do seu entorno, até então com alto nível de dependência da economia algodoeira.

Apesar da crise econômica, na década de 70 Caicó foi alvo de investimentos e iniciativas que estavam associadas às políticas públicas urbanas em voga, à tentativa de mitigação dos problemas socioeconômicos decorrentes da crise da cotonicultura e às novas demandas provenientes do processo de crescimento e desenvolvimento socioespacial pelas quais a cidade vinha passando nas décadas anteriores.

Nesse contexto, a cidade de Caicó teve acrescido ao seu arranjo espacial três novas manchas urbanas: o Conjunto Habitacional Castello Branco e os bairros Paulo VI e Walfredo Gurgel, os quais caracterizaram-se por uma ocupação realizada por pessoas de baixa renda (MORAIS, 1999). Ademais, em termos de infraestrutura urbana, destacam-se a instalação da Loja Maçônica Regeneração do Seridó, da Associação Comercial de Caicó, do Núcleo Avançado de Caicó - NAC/UFRN, da 7ạ Companhia de Infantaria Motorizada, do Centro de Serviços Urbanos - CSU, da Estação Rodoviária Manoel de Neném, do Centro Regional de Agricultura e das agências bancárias (Caixa Econômica Federal, Banco Brasileiro de Descontos S/A - Bradesco - e Banco do Nordeste do Brasil - BNB (MORAIS, 1999, p. 15).

\footnotetext{
11Esses fatores já foram amplamente estudados por diversos autores, entre os quais, destacam-se ARAÚjO (2008), DANTAS (2001), MORAIS (1999), FARIA (2011).
} 
Desse modo no ano de 1980, como reflexo do processo de crescimento urbano antecedente, a cartografia de Caicó revelava que o processo de expansão urbana havia repercutido em todas as zonas geográficas da cidade (Figura 3). O arranjo espacial citadino, no referido ano, correspondia a 11 bairros (incluindo o Centro), registrando tendências de maior crescimento na zona oeste, na qual se concentrava a população mais pobre.

Figura 3 - Cidade de Caicó - 1980

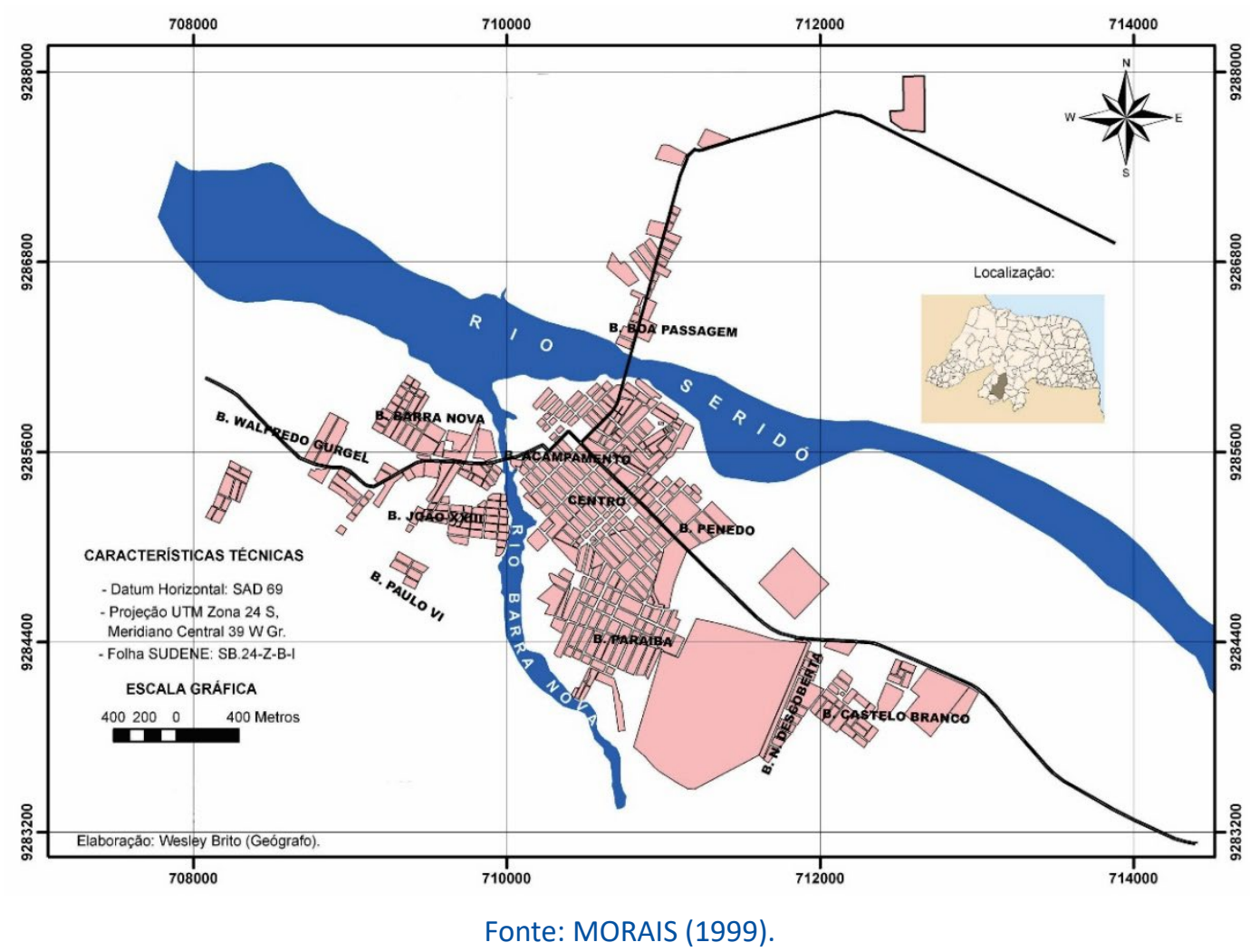

Sendo este o limiar para a terceira fase da expansão urbana de Caicó, que compreende a década de 80 aos dias atuais - cenário pós-crise da cotonicultura - define-se como característica marcante o que se chamou de reestruturação produtiva. Nessa fase a economia do município de Caicó, antes centrada no binômio algodão-gado, passou a se basear no setor terciário. De acordo com Faria (2011, p. 96), "surge um evento novo ligado ao setor terciário, estamos nos referindo às repartições públicas e privadas e lojas comerciais que deflagraram na cidade de Caicó um novo período técnico".

Nesse contexto, também o setor industrial passou por mudanças, visto que ocorreu o fechamento das usinas de beneficiamento do algodão, mas surgiram estabelecimentos ligados a outros segmentos produtivos, como tecelagem, chapelaria, panificadora e carpintaria.

Quanto à dinâmica populacional, os dados revelam a manutenção da tendência de crescimento da população, especialmente da urbana, embora em ritmo de desaceleração (Tabela 2). 
Tabela 2 - População Total, Urbana e Rural de Caicó - 1980 - 2010

\begin{tabular}{c|c|c|c|}
\hline \multirow{2}{*}{ Censo } & \multicolumn{3}{|c|}{ População } \\
\cline { 2 - 4 } & Total & Urbana & Rural \\
\hline 1980 & 40.028 & 30.793 & 9.235 \\
1991 & 50.658 & 42.801 & 7.857 \\
2000 & 57.002 & 50.624 & 6.378 \\
2010 & 62.709 & 57.461 & 5.248 \\
\hline
\end{tabular}

Fonte: Censos Demográficos do IBGE (1980, 1991, 2000, 2010).

Nesse cenário de crescimento populacional, verificou-se uma expressiva ampliação e diversificação do comércio e dos serviços. De acordo com Faria (2011), no segmento comercial destacam-se os empreendimentos de revenda de automóveis, gêneros alimentícios, vestuário, ótica, entre outros. No setor de serviços sobressaem aqueles vinculados à saúde e educação, tanto públicos quanto privados.

No setor educacional, Faria (2011) observa que a demanda pelo serviço ocorre desde o nível de creche ao universitário. Na cidade há seis instituições de ensino superior, das quais quatro são públicas (Universidade Federal do Rio Grande do Norte UFRN - , Universidade Estadual do Rio Grande do Norte - UERN - , Universidade Estadual Vale do Acaraú - UVA - e Instituto Federal do Rio Grande do Norte - IFRN) e duas são particulares (Faculdade de Teologia Cardeal Eugênio Sales - FCS e Faculdade Católica Santa Teresinha - FST).

O crescimento do setor de serviços, no período em análise, teve como fator fundamental as políticas públicas, que visavam a mitigar as consequências da crise econômica, por meio da instalação de instituições prestadoras de serviços e de equipamentos urbanos. De acordo com Faria (2011, p. 108), entre as instituições e equipamentos instalados estão: Estádio Marizão (1983), Associação Atlética Banco do Brasil - AABB (1983), Hospital Regional do Sesp (1990), Centro de Atenção Integral à Criança - Caic (1994), Ponte José Josias Fernandes (1999), Universidade Federal do Rio Grande do Norte - UFRN (1979), Presídio Desembargador Francisco Pereira da Nóbrega (1998).

Essas iniciativas serviram para ratificar a centralidade urbano-regional de Caicó, manter as condições de atratividade populacional e, por conseguinte, o processo de expansão urbana.

A centralidade urbano-regional que Caicó apresenta é ratificada por Faria (2011, p. 72-73), que assim se manifesta:

Todos os dias, a cidade é receptora e fornecedora de produtos de toda ordem. Supermercados, lojas de elétrico eletrônicos e eletrodomésticos, armazéns e lojas de produtos da construção civil, indústrias têxteis geram um impressionante movimento, no que diz respeito à circulação e consumo das mais diversas mercadorias. No setor de prestação de serviços, os bancos (Banco do Brasil, Caixa Econômica Federal e Bradesco), como, também, postos de serviços dessas instituições financeiras, hospitais, escolas de ensino médio, universidades, faculdades, sedes dos serviços públicos mais importantes e uma Central do Cidadão perfazem a dinâmica desse setor que movimenta a cidade e a ela ratifica o cunho de área core ou centro regional. 
Nessa tessitura, população e economia aparecem como elementos de uma trama que se revela na espacialização da cidade, mediante a ampliação dos bairros existentes e o surgimento de novos, configurando-se variáveis do processo de expansão urbana, que se evidencia em todas as zonas geográficas da cidade. Entre 1980 e 2016 a cidade passou de 11 para 29 bairros (Figura 4).

Figura 4 - Cidade de Caicó, por bairros - 2016

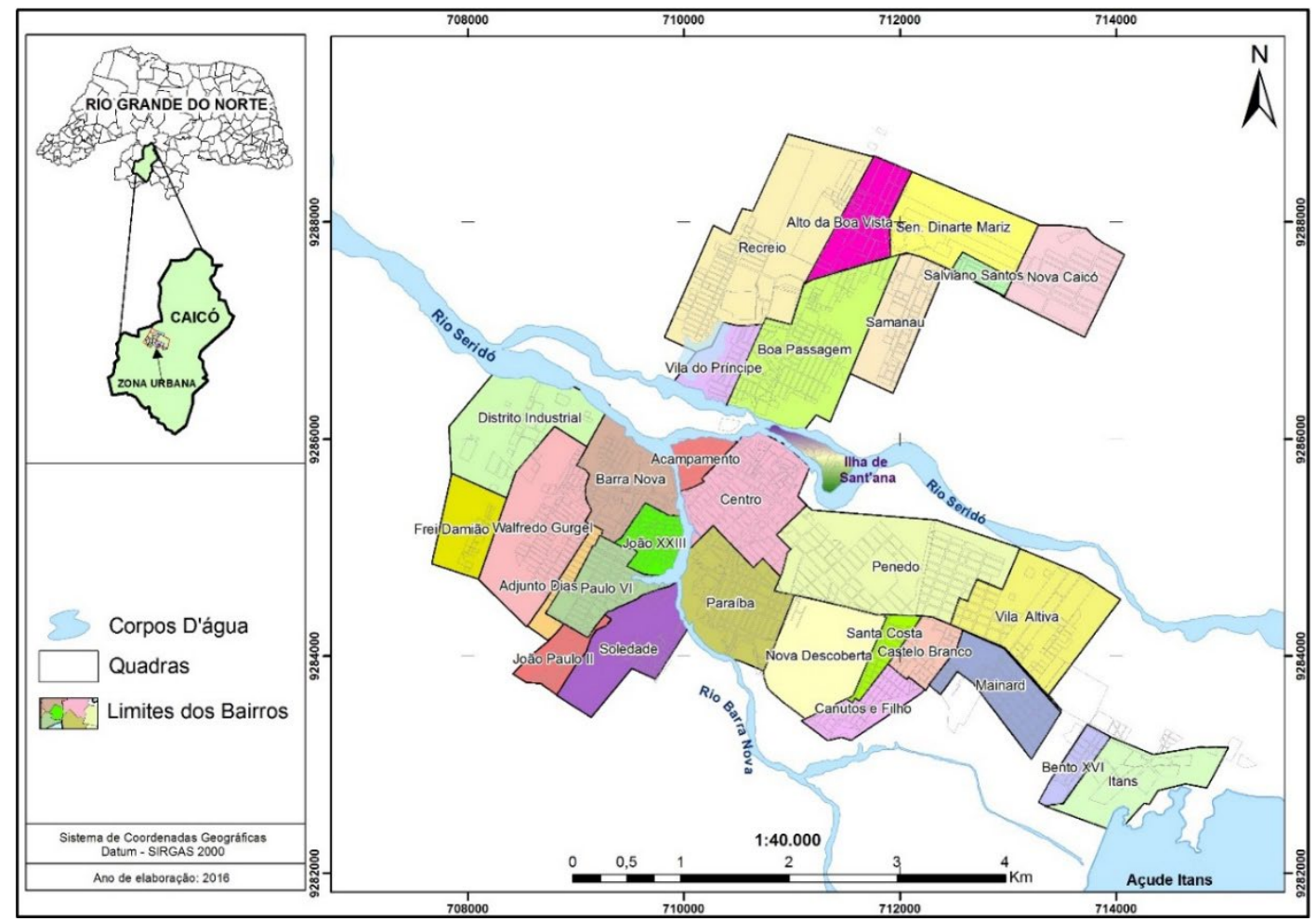

Fonte: Adaptado de AGÊNCIA DOS CORREIOS (2014); COMPANHIA... (2015).

Considerando que a expansão urbana de Caicó efetivou-se por meio do adensamento populacional, é possível concluir que as zonas Oeste e Norte foram as que registraram maior impacto desse processo, sobretudo quando se considera a variável espacialização. Nesse sentido, sistematizou-se informações sobre os bairros de formação antiga, ou seja, aqueles que se constituíram até o ano de 1980, e os bairros de formação recente, os quais surgiram após o citado ano (Quadro 2).

Quadro 2 - Cidade de Caicó, por zonas e bairros, quanto ao período de formação - 1980/2016

\begin{tabular}{|c|c|c|}
\hline \multirow{2}{*}{$\begin{array}{c}\text { Zonas } \\
\text { Geográficas }\end{array}$} & \multicolumn{2}{|c|}{ Bairros } \\
\hline & Formação Antiga (até 1980) & Formação Recente (após 1980) \\
\hline Centro & $\begin{array}{l}\text { Centro } \\
\text { Acampamento }\end{array}$ & - \\
\hline Sul & $\begin{array}{l}\text { Nova Descoberta } \\
\text { Castelo Branco } \\
\text { Paraíba }\end{array}$ & $\begin{array}{l}\text { Soledade } \\
\text { Canutos e Filhos } \\
\text { Bento XVI } \\
\text { Santa Costa } \\
\text { Mainard } \\
\text { Itans* }\end{array}$ \\
\hline
\end{tabular}




\begin{tabular}{|c|l|l|}
\hline \multirow{2}{*}{ Norte } & Boa Passagem & $\begin{array}{l}\text { Vila do Príncipe } \\
\text { Recreio } \\
\text { Samanaú, } \\
\text { Salviano Santos } \\
\text { Alto da Boa Vista } \\
\text { Senador Dinarte Mariz } \\
\text { Nova Caicó }\end{array}$ \\
\hline Oeste & $\begin{array}{l}\text { Falfredo Gurgel } \\
\text { Paulo VI } \\
\text { João XXIIII } \\
\text { Jarra Nova Paulo II } \\
\text { Adjunto Dias } \\
\text { Distrito Industrial }\end{array}$ \\
\hline Leste & Penedo & Vila Altiva \\
\hline
\end{tabular}

Fonte: Elaboração dos autores.

*em 1980 não era considerado parte da zona urbana.

A análise acerca da expansão urbana de Caicó permite concluir acerca da ocorrência de um processo, que se revela por meio da dinâmica da população, da economia e da espacialização citadina. Nesse sentido, considerando a problematização do trabaIho, buscar-se-á analisar a relação entre expansão urbana e vulnerabilidade socioeconômica.

\section{A CIDADE E A CARTOGRAFIA DA VULNERABILIDADE SOCIOECONÔMICA}

No âmbito das discussões sobre expansão urbana, os estudos que contemplam as condições de vida vêm adquirindo importância, tendo em vista que, no capitalismo, a cidade, na condição de uma construção social e histórica (CARLOS, 2007), revela-se perpassada por desigualdades que se refletem no espaço. Sendo assim, o viver na cidade, por vezes, torna a população, sobretudo a mais pobre, vulnerável tanto do ponto de vista socioeconômico quanto ambiental, requisitando dos entes governamentais a adoção de ações que visem a superar ou mitigar esse quadro.

Segundo Brandão (1992), à medida que se intensifica a ocupação urbana agravam-se os problemas socioambientais, evidenciando as fragilidades da infraestrutura citadina e ampliando os níveis de vulnerabilidade.

Dessa forma, a preocupação com os problemas decorrentes da expansão urbana, bem como em relação às condições de vida da população residente em áreas periféricas deterioradas, geralmente marcadas pela precarização de infraestrutura em termos de coleta de lixo, abastecimento de água, drenagem, pavimentação de ruas e esgotamento sanitário, está na pauta de estudiosos, planejadores e gestores. Acrescente-se, ainda, a precarização ou ausência de instituições de saúde, educação, segurança pública, lazer e transportes, entre outros, que fragilizam e comprometem as condições de vida das pessoas nas cidades.

Os estudos sobre essa temática têm contemplado aspectos sociais, econômicos e ambientais. Nessa tessitura, adquire proeminência as abordagens sobre vulnerabilidade socioambiental que, segundo Alves (2006, p. 6), define-se como "a coexistência, cumulatividade ou sobreposição espacial de situações de pobreza/privação social e de situa- 
ções de exposição a risco e/ou degradação ambiental". Entre os autores que discutem a vulnerabilidade socioambiental destacam-se Deschamps (2004), Hogan; Marandola Júnior (2006), Almeida (2010), Alves et al (2010a, 2010b) e Maior (2014).

De acordo com a abordagem de Maior (2014) acerca da vulnerabilidade socioambiental, esta apresenta duas dimensões: socioeconômica e ambiental. A vulnerabilidade socioeconômica abrange os temas condições domiciliares, infraestrutura urbana, condições dos chefes de família, composição familiar e dependência, situação educacional da família, renda, situação do trabalho. A vulnerabilidade ambiental abrange o tema comunidades em risco.

Neste estudo o enfoque recaiu sobre a vulnerabilidade socioeconômica tendo sido considerados 7 temas, que compreendem 13 grupos de indicadores e 29 indicadores (MAIOR, 2014). A definição dos índices e o estabelecimento de sua classificação em níveis tornaram possível a geração do Mapa da Vulnerabilidade Socioeconômica da Cidade de Caicó, por bairros (Figura 5).

Figura 5 - Níveis de Vulnerabilidade Socioeconômica da Cidade de Caicó, por Bairros - 2016

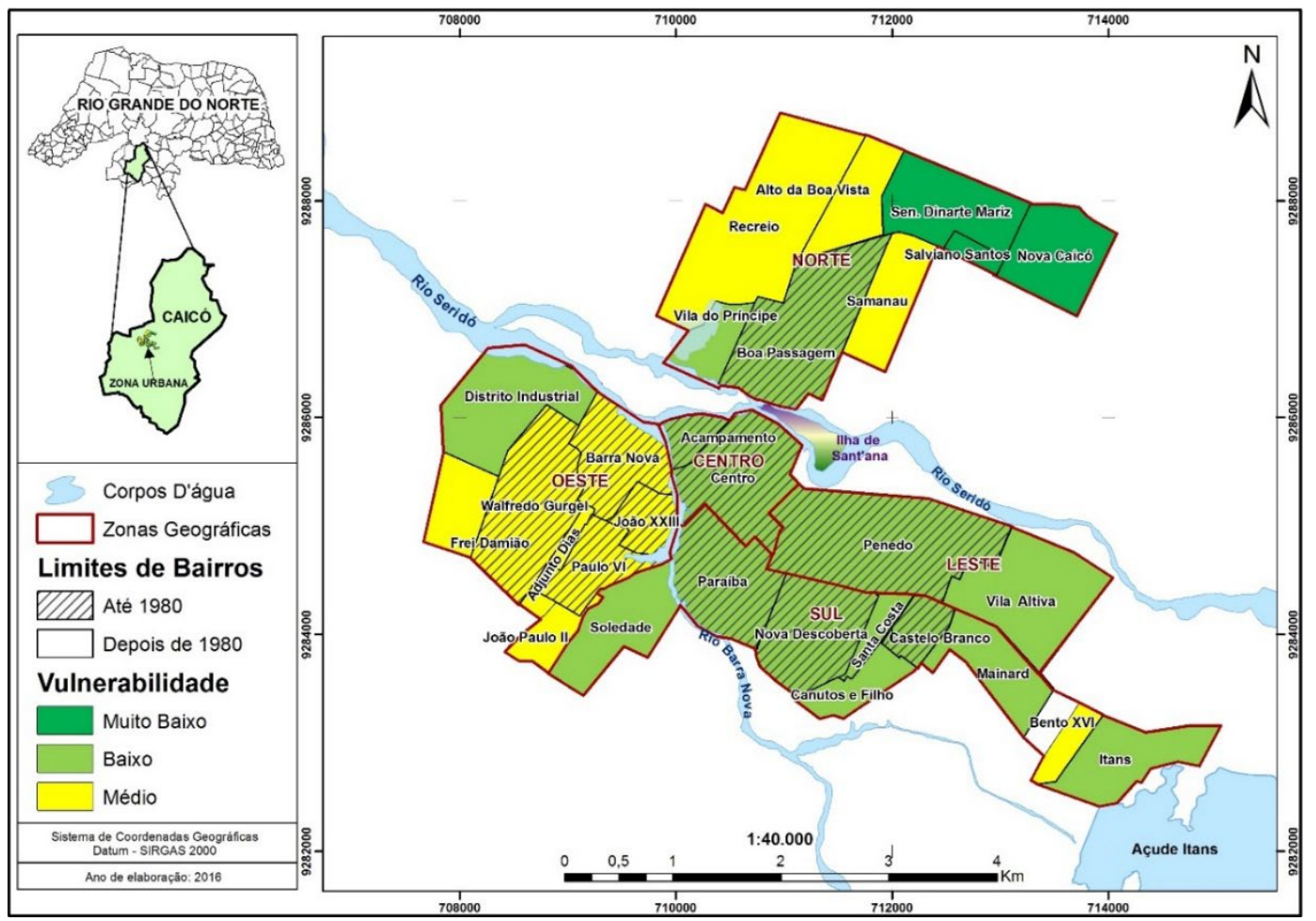

Fonte: AGÊNCIA DOS CORREIOS (2014); COMPANHIA... (2015); IBGE (2016a).

De acordo com os dados obtidos, o IVSB de Caicó oscila entre os níveis muito baixo e médio, predominando o nível baixo. Dos 29 bairros existentes na cidade em 2016, 11 foram classificados com nível médio, $15 \mathrm{com}$ nível baixo e $3 \mathrm{com}$ nível muito baixo de vulnerabilidade socioeconômica. Quanto ao IVSB, dos 11 bairros de formação antiga, 7 apresentaram nível baixo e 4 nível médio, e dos 18 bairros de formação recente, 3 registraram nível muito baixo, 8 nível baixo e 7 nível médio. A variação do IVSB entre os bairros da cidade oscila de 0,164 , índice considerado baixo, que foi registrado nos bairros Salviano Santos, Nova Caicó e Senador Dinarte Mariz, localizados na Zona Norte, e 0,569, índice considerado médio, que foi notificado no bairro João Paulo II, na Zona Oeste. 
Essas inferências tornam-se mais evidentes a partir da análise do IVSB, por zona e período de formação dos bairros da cidade de Caicó.

A Zona Central de Caicó compreende o Centro e o bairro Acampamento; ambos são de formação antiga. O Centro corresponde à área em que se originou a cidade, caracterizando-se pela conformação do complexo histórico-cultural formado pelos Largos da Igreja do Rosário, Praça Senador Dinarte Mariz e Largo da Catedral de Sant'Ana (MORAIS, 1999). Nele também encontra-se o eixo de cruzamento das avenidas Coronel Martiniano e Renato Dantas, que corta a cidade no sentido leste/oeste, com a Avenida Seridó, que a atravessa no sentido norte-sul, configurando-se o núcleo central da cidade, onde localiza-se o centro comercial (óticas, lojas, supermercados, farmácias, bancos, hotéis, restaurantes, barracos, bares, o Mercado Público, duas feiras livres, açougue público). Também abriga sede de instituições prestadoras de serviços, como a Mesa de Rendas Estaduais, a Delegacia Regional do Trabalho, escritórios de advocacia, clínicas médico-odontológicas, escritórios de contabilidade, Escola Multicampi de Ciências Médicas/UFRN, Rodoviária Manuel de Neném, Prefeitura e Secretarias Municipais, Biblioteca Pública, Fórum Municipal, Câmara de Vereadores, Museu do Seridó, entre outros. O bairro do Acampamento corresponde a uma área predominantemente residencial, com específica localização geográfica entre a zona central e os rios Seridó e Barra Nova, o que limita sua expansão.

Com relação ao IVSB, os dois bairros que conformam a Zona Central apresentam nível baixo, entretanto, entre os 29 indicadores analisados, 2 apresentam alta vulnerabilidade: famílias chefiadas por pessoas idosas e famílias dependentes de pessoas idosas. Essa situação ratifica a premissa de que há vulnerabilidade socioeconômica quando os domicílios dependem financeiramente de pessoas idosas. Isso porque, em alguns casos, "a aposentadoria tem se transformado na única fonte de renda da família", o que "reflete que os filhos ou netos estão recaindo sobre a responsabilidade do primeiro provedor, fazendo-o redistribuir sua aposentadoria para outros familiares" (MAIOR, 2014, p. 129).

$\mathrm{Na}$ Zona Sul da cidade, dos nove bairros existentes, três são de formação antiga e detêm IVSB baixo (Nova Descoberta, Castelo Branco e Paraíba), enquanto seis são de formação recente e, entre estes, cinco apresentam IVSB baixo (Soledade, Itans, Canutos e Filhos, Santa Costa e Maynard) e apenas um possui IVSB médio (bairro Bento XVI). Nessa zona os bairros que merecem ressalva são: o Paraíba, de formação antiga, que apresenta nível alto nos indicadores famílias chefiadas por pessoas idosas; o Soledade, Santa Costa e Mainard, de formação recente, que apresenta nível alto no que diz respeito a pessoas morando em domicílios alugados e pessoas menores de idade. O pagamento de aluguel é uma condição que proporciona

vulnerabilidade sob dois aspectos: o primeiro porque exige um desprendimento de uma boa parte da renda para seu pagamento; e o segundo porque não permite a reformulação do espaço de acordo com a necessidade de espaço da família locadora (MAIOR, 2014, p. 106).

A dependência financeira de pessoas menores de idade representa uma grande vulnerabilidade socioeconômica, visto que os menores que assumem essa responsabilidade perdem oportunidades concernentes a sua faixa etária. "A responsabilidade de 
mantimento familiar leva o jovem a abandonar logo cedo a escola, refletindo na sua ocupação no mercado de trabalho, como baixos rendimentos e informalidade no trabaIho" (MAIOR, 2014, p. 127).

Na Zona Oeste da cidade, dos oito bairros que a compõem, quatro são de formação antiga e possuem IVSB médio (Walfredo Gurgel, Paulo VI, João XXIII e Barra Nova) e quatro são de formação recente, edestes, três apresentam IVSB médio (Frei Damião, João Paulo II e Adjuto Dias) e apenas um notificou IVSB baixo (Distrito Industrial). Ressalta-se ainda que, a despeito dos índices calculados para o Frei Damião e o João Paulo II terem apontado para um IVSB médio, os referidos bairros da Zona Oeste apresentam nível alto em relação a domicílios particulares permanentes inadequados e a domicílios particulares permanentes sem banheiros. Neste caso, tem-se uma outra feição da vulnerabilidade socioeconômica que se revela mediante uma

situação de inadequação da habitação quando esta faz uso comum de instalações hidráulica e sanitária (banheiro, cozinha, tanque, etc.) com outras moradias e utilização do mesmo ambiente para diversas funções (dormir, cozinhar, fazer refeições, trabalhar, etc.) (MAIOR, 2014, p. 114).

Ainda em relação ao bairro João Paulo II, a elevada vulnerabilidade socioeconômica também se revela em termos de famílias chefiadas por pessoas jovens, o que "é considerado como fator de agravamento da vulnerabilidade quando jovens, ainda em processo de formação, precisam abandonar a escola para prover o sustento familiar" (CORREIA, 2016, p. 34); mulheres não alfabetizadas com baixos rendimentos responsáveis por domicílios, que é emblemático da situação de vulnerabilidade, pois aponta desvantagens do gênero feminino "sobreposto à situação de analfabetismo e baixos rendimentos, caracterizando, assim, as mulheres chefes de família excluídas socioeconomicamente do mercado de trabalho" (MAIOR, 2014, p. 141); jovens adultos analfabetos (19 a 30 anos) e pessoas analfabetas de 5 a 14 anos de idade, sendo considerado que o analfabetismo impacta na renda, "uma vez que pessoas nestas condições não têm acesso a empregos especializados e, consequentemente, com melhor remuneração, estando inseridos de maneira precária no mercado de trabalho" (CORREIA, 2016, p. 37).

A Zona Norte de Caicó apresenta diferenças em termos de níveis de vulnerabilidade socioeconômica. Dos oito bairros que a integram, somente um é de formação antiga e registra IVSB baixo (Boa Passagem); entre os sete de formação recente, um possui IVSB baixo (Vila do Príncipe), três foram classificados com IVSB muito baixo (Salviano Santos, Senador Dinarte Mariz e Nova Caicó) e três detêm IVSB médio (Recreio, Samanaú e Alto da Boa Vista) de vulnerabilidade socioeconômica. Os bairros Recreio, Samanaú e Alto da Boa Vista apresentam níveis altos de vulnerabilidade socioeconômica em termos de pessoas morando em domicílios alugados, o que revela fragilidade, visto que "as famílias que se encontram em situação de aluguel empregam parte da sua renda para pagamento de uma moradia que não lhes pertence" (CORREIA, 2016, p. 33); Responsáveis por domicílios particulares permanentes com rendimento mensal de até 2 SM, pois os baixos rendimentos são reflexo de situações extrema de pobreza e falta de oportunidades e baixos níveis educacionais; famílias com alta frequência de componentes e pessoas menores de idade (10 anos a 14 anos). A realidade das famílias 
desses bairros revela vulnerabilidade socioeconômica, o que é preocupante devido às condições de vida e às restritas possibilidades que se apresentam para as pessoas mais pobres.

Na Zona Leste de Caicó os dois bairros que a constituem apresentam IVSB baixo. Apesar disso, o bairro Penedo, de formação antiga, apresenta alta vulnerabilidade nos indicadores pessoas idosas (com 64 anos ou mais) e famílias com rendimento de até dois a cinco salários mínimos. O Vila Altiva apresenta índices médios em quatro indicadores: pessoas morando em domicílios alugados, pessoas agregados na família, pessoas menores de idade (10 a 14 anos) e famílias com rendimento de até dois salários mínimos. O Vila Altiva, de formação recente, também foi classificado com IVSB baixo.

Nesse contexto, a avaliação dos índices e níveis de vulnerabilidade socioeconômica de Caicó, a partir do conjunto de bairros de cada zona, indica que nenhum deles possui IVSB alto e que não há expressivas variações. Os dados, entretanto, revelam que a Zona Oeste é a que apresenta maior vulnerabilidade socioeconômica, com o bairro João Paulo II sendo o que detém o mais elevado índice na cidade. Outrossim, também se constata que, embora o IVSB médio tenha sido registrado em bairros de formação antiga, sua ocorrência mostra-se mais contundente entre os bairros de formação recente.

Nessa perspectiva, é possível inferir que existe relação entre expansão urbana e vulnerabilidade socioeconômica, tendo em vista que este fenômeno torna-se mais presente em bairros de formação recente, em geral situados na periferia das cidades, na qual se concentram populações de menor poder aquisitivo e as políticas públicas são mais negligenciadas.

\section{CONSIDERAÇÕES FINAIS}

A análise da expansão urbana de Caicó, a partir das variáveis população, economia e espacialização citadina, permitiu o estabelecimento de uma periodicidade que abrange três fases, as quais se configuram a partir de aspectos associados a contextos históricos específicos. Entre estes tem-se a produção algodoeira como baliza para definir os cenários do auge, da crise e do pós-crise dessa economia, que compunha a base produtiva do município.

Sendo o cenário pós-crise da cotonicultura (da década de 80 aos dias atuais) definido como marco temporal prioritário da análise, a leitura da expansão urbana de Caicó foi realizada a partir da população, economia e espacialização citadina. Nesta perspectiva, registra-se que as variáveis em análise apresentaram tendência de crescimento em um processo no qual o padrão de comportamento da população influenciou a dinâmica do terciário e a ampliação do número de bairros da cidade. Acrescente-se, ainda, que a economia terciária passou a ser predominante no contexto de declínio da cotonicultura, que afetou o binômio gado-algodão.

Em decorrência do processo de expansão urbana recente, verificou-se que, no ano de 2016, Caicó conta com 29 bairros, dos quais 11 foram considerados de formação antiga e 18 de formação recente. 
Considerando essa configuração citadina, tem-se que os índices e níveis de vulnerabilidade socioeconômica de Caicó, por bairros e zonas geográficas, oscilam entre muito baixo e médio. No âmbito da cidade, a Zona Oeste é a que registra maior vulnerabilidade socioeconômica e o bairro João Paulo II, situado na referida zona, é o que apresenta o IVSB mais elevado.

Depreende-se dos dados obtidos que o IVSB registrou nível médio tanto em bairros de formação antiga quanto recente, mas é nestes últimos que sua ocorrência é mais representativa; possivelmente em decorrência da localização periférica, da concentração de populações de menor poder aquisitivo e, por conseguinte, de menor intervenção de políticas públicas. Delineado esse arcabouço analítico, infere-se que o fenômeno da vulnerabilidade socioeconômica apresenta relação como o processo de expansão urbana.

\section{REFERÊNCIAS}

ABRAMOVAY, M. et al. Juventude, violência e vulnerabilidade social na América Latina: desafios para políticas públicas. Brasília: Unesco, 2002.

AGÊNCIA DOS CORREIOS. Caicó/RN. 2014.

ALMEIDA, Lutiane Queiroz de. Vulnerabilidade socioambiental de rios urbanos. Bacia hidrográfica do Rio Maranguapinho. 2010. 278 f. Tese (Doutorado em Geografia) - Instituto de Geociência e Ciência Exatas, Unesp, Rio Claro, Região Metropolitana de Fortaleza, Ceará, 2010.

ALVES, H. P. da F. et al. Dinâmicas de urbanização na hiperperiferia da metrópole de São Paulo: análise dos processos de expansão urbana e das situações de vulnerabilidade socioambiental em escala intraurbana. Revista Brasileira de Estudos Populacionais, Rio de Janeiro, v. 7, n. 1, p. 141-159, jan./jun. 2010 a.

ALVES, H. P. da F. et al. Vulnerabilidade socioambiental nos municípios do litoral paulista no contexto das mudanças climáticas. ENCONTRO NACIONAL DE ESTUDOS POPULACIONAIS, 17., 2010. Caxambu. Anais [...] Caxambu, MG, Brasil, 20 a 24 de setembro de 2010b.

ALVES, H. P. da F. Vulnerabilidade socioambiental na metrópole paulistana: uma análise sociodemográfica das situações de sobreposição espacial de problemas e riscos sociais e ambientais. Revista Brasileira de Estudos Populacionais, São Paulo, v. 23, p. 43-59, n. 1, jan./jun. 2006.

ALVES, H. P. F.; TORRES, H. G. Vulnerabilidade socioambiental na cidade de São Paulo: uma análise de famílias e domicílios em situação de pobreza e risco ambiental. São Paulo em Perspectiva, São Paulo, Fundação Seade, v. 20, n. 1, p. 44-60, jan./mar. 2006.

ARAÚJO, M. A. A. Sobre pedras, entre rios: modernização do espaço urbano de Caicó/RN (1950/1960). 2008. Dissertação (Mestrado em Geografia) - UFRN, Natal, RN, 2008.

BRANDÃO, A. M. P. M. As alterações climáticas na área metropolitana do Rio de Janeiro: uma provável influência do crescimento urbano. In: ABREU, M. A. (org.). Natureza e Sociedade no Rio de Janeiro. Rio de Janeiro: Secretaria Municipal de Cultura, Turismo e Esportes, 1992. p. 143-200. (Coleção Biblioteca Carioca, vol. 21).

CARLOS, A. F. A. A cidade. São Paulo: Contexto, 2007.

CLEMENTINO, M. do L. M. O maquinista de algodão e o capital comercial. Natal: Ed. Universitária, 1987.

CLEMENTINO, M. do L. M.; SOUZA, M. A. DE A. Conjuntura urbana: como andam Natal e Recife. Rio de Janeiro: Letra Capital - Observatório das Metrópoles, 2009. V. 6.

COMPANHIA DE ÁGUAS E ESGOTOS DO RIO GRANDE DO NORTE (Caern). Caicó/RN. 2015.

CORREIA, L. A. M. B. Vulnerabilidade socioambiental: análise da cidade do Natal/RN a partir do índice geral de vulnerabilidade socioambiental por bairro. 2016. Dissertação (Mestrado em Desenvolvimento e Meio Ambiente) - UFRN, Programa Desenvolvimento e Meio Ambiente - Prodema, Natal, RN, 2016.

DANTAS, Manoel. Homens de Outrora. Natal, RN: Sebo Vermelho, 2001.

DESCHAMPS, M. V. Vulnerabilidade socioambiental na Região Metropolitana de Curitiba. Tese (Doutorado em Meio Ambiente e Desenvolvimento) - UFPR, Curitiba, PR, 2004.

FARIA, C. E. de. Os eventos geográficos e a expansão urbana de Caicó: desigualdades e coexistências na urbe. Natal, RN. Ed.: IFRN, 2011.

HOGAN, Daniel Joseph; MARANDOLA JÚNIOR, Eduardo. As dimensões da vulnerabilidade. São Paulo em Perspectiva, São Paulo, v. 20, n. 1, p. 33-43, jan./mar. 2006. 
IBGE. Instituto Brasileiro de Geografia e Estatística. Censos demográficos: 1940, 1950, 1960, 1970, 1980, 1990, 2000 e 2010. Disponível em: http://www.ibge.gov.br. Acesso em: 20, 21 e 22 maio e 10, 11 e 15 jun. 2016a.

IBGE. Instituto Brasileiro de Geografia e Estatística. Produto Interno Bruto (PIB). Disponível em: http:// www.deepask.com/goes?page=caico/RN-Confira-o-PIB---Produto-Interno-Bruto---no-seu-municipio. Acesso em: 11 jul. $2016 \mathrm{~b}$.

IBGE. Instituto Brasileiro de Geografia e Estatística. Estimativas de população para 10 de julho de 2015. Disponível em: ftp://ftp.ibge.gov.br/Estimativas_de_Populacao/Estimativas_2015/estimativa_2015_ TCU_20160712.pdf. Acesso em: 16 jul. 2016c.

IBGE. Instituto Brasileiro de Geografia e Estatística. Regiões de Influências das Cidades. Rio de Janeiro, 2007. http://www.mma.gov.br/estruturas/PZEE/_arquivos/regic_28.pdf.

MAIOR, M. M. S. Vulnerabilidade socioambiental e o processo de transbordamento urbano: uma proposta de metodologia para análise das suas relações. 2014. Tese (Doutorado em Recursos Naturais) - UFCG, Campina Grande, PB, 2014.

MORAIS, I. R. D. Desvendando a cidade: Caicó em sua dinâmica espacial. Brasília: Senado Federal, 1999. PRIEM, R.; SHAFFER, M. Resolving moral dilemmas in business: a multicountry study. Business and Society, n. 40, v. 2, p. 197-219. 2001. 